\title{
A PARTICIPAÇÃO DA CRIANÇA NA PESQUISA: entre possibilidades e limites
}

\author{
LA PARTICIPACIÓN DEL NIÑO EN LA INVESTIGACIÓN: entre posibilidades y \\ limites
}

CHILD'S PARTICIPATION IN RESEARCH: between possibilities and limits

\author{
Marta Regina Brostolin ${ }^{1}$ \\ ORCID: http://orcid.org/0000-0003-4262-2222 \\ Ana Paula Zaikievicz Azevedo ${ }^{2}$ \\ ORCID: https://orcid.org/0000-0001-6737-9404
}

\begin{abstract}
Resumo
Este texto, recorte de uma pesquisa de Mestrado, tece reflexões acerca da participação de crianças em pesquisa. A intenção não é analisar os resultados da pesquisa realizada, mas sim refletir acerca das possibilidades e limites que a pesquisa com crianças nos impõe como processo investigativo denso que necessita de muito estudo, planejamento, organização e ética. A pesquisa ancora-se na Sociologia da Infância, pois esse campo teórico defende as crianças enquanto sujeitos de direitos, produtores de culturas e de saberes, que precisam ser escutadas e respeitadas. Com o desenvolvimento da pesquisa foi possível constatar que o exercício de pesquisar com criança não é um processo simples, mas um exercício que exige, cuidado, sensibilidade, ética, flexibilidade e amplo conhecimento sobre a infância por parte do pesquisador, pois, envolver as crianças na pesquisa, torna-se um importante mecanismo de reconhecimento destas enquanto autores e atores de suas próprias histórias que merecem ser escutadas e respeitados pelas suas singularidades.
\end{abstract}

Palavras-chave: Pesquisa com crianças. Sociologia da Infância. Possibilidades. Limites.

\section{Resumen}

Este texto, que forma parte de una investigación de Maestría, reflexiona sobre la participación de los niños en la investigación. La intención no es analizar los resultados de la investigación realizada, sino reflexionar sobre las posibilidades y límites que nos impone la investigación con niños como un proceso de investigación denso que requiere mucho estudio, planificación, organización y ética.

\footnotetext{
1 Doutorado em Educação. Estágio Pós-doutoral - Universidade do Minho, Braga/Portugal. Docente da Universidade Católica Dom Bosco - UCDB no Curso de Pedagogia e Programa de Pós-Graduação em Educação Mestrado e Doutorado. Líder do GEPDI - Grupo de Estudos e Pesquisas da Docência na Infância. Email:brosto@ucdb.br

2 Mestrado em Educação. Docente no curso de Pedagogia da Universidade Católica Dom Bosco - UCDB. Membro do Grupo de Estudos e Pesquisas em Teoria Sócio-Histórica, Migrações e Gênero, do Programa de Pós-Graduação em Psicologia da Universidade Católica Dom Bosco. E-mail: anapaulaz20@ hotmail.com
}

\section{Como citar esse artigo:}

BROSTOLIN, M. R; AZEVEDO, A. P. Z. A participação da criança na pesquisa: entre possibilidades e limites. Revista Pedagógica, v. 23, p. 1-19, 2021 DOI http://dx.doi.org/10.22196/rp.v22io.5780 
La investigación está anclada en la Sociología de la Infancia, ya que este campo teórico defiende a los niños como sujetos de derechos, productores de culturas y conocimientos, que necesitan ser escuchados y respetados. Con el desarrollo de la investigación se pudo constatar que el ejercicio de investigar con niños no es un proceso simple, sino un ejercicio que requiere al investigador, cuidado, sensibilidad, ética, flexibilidad y amplios conocimientos sobre la niñez, porque involucrar a los niños en la investigación, se convierte en un mecanismo importante para reconocer a los niños como autores y actores de sus propias historias que merecen ser escuchadas y respetadas en sus singularidades.

Palabras clave: Investigación con niños. Sociología de la Infancia. Posibilidades. Límites.

\begin{abstract}
This text, part of a Master's research, reflects on the participation of children in research. The purpose of this text is not to analyze the results of the research carried out, but to reflect about the possibilities and limits that research with children imposes on us as a dense investigative process that requires a lot of study, planning, organization and ethics. The research is anchored in the Sociology of Childhood, as this theoretical field defends children as subjects of rights, producers of cultures and knowledged, who need to be heard and regarded. With the development of the research it was possible to verify that the exercise of researching with children is not a simple process, but an exercise that requires care, sensitivity, ethics, flexibility and ample knowledge about childhood by the researcher, because it involves children in research, it becomes an important mechanism for recognizing children as authors and actors of their own stories that deserve to be heard and respected by their singularities.
\end{abstract}

Keywords: Research with children. Sociology of Childhood. Possibilities. Limits.

\title{
INTRODUÇÃO
}

Toda pesquisa necessita de ancoragem teórica que lhe propicie sustentação e permita encontrar formas válidas e adequadas de questionar e de recolher as vozes e ações das crianças com rigor ético. A criança é um outro distinto do adulto e, assim o é, também no seu grupo de pares. Esta alteridade é um desafio para o investigador e exige uma significativa criação metodológica que se coloca na interdependência entre o mundo da criança e do adulto. A ideia de possibilitar acesso a voz da criança envolve processos dialógicos que devem assegurar a alteridade de crianças e adultos.

Nesta perspectiva, a Sociologia da Infância mostra-se um espaço fértil para a pesquisa com crianças, colocando vários desafios em relação aos desenhos metodológicos e na interpretação de diferentes instrumentos de investigação como forma de escutar as crianças por meio de suas próprias linguagens e formas de compreender o mundo. 
Observando-as em seu contexto, percebendo suas interações numa perspectiva interpretativa e crítica, assegurando que sua participação se torne audível e visível em suas dinâmicas (FERNANDES; TREVISAN, 2018).

Neste contexto insere-se este texto, recorte de uma pesquisa de Mestrado que teve por objetivo compreender as manifestações das crianças da pré-escola sobre a instituição de Educação Infantil que frequentavam, destacando que escutar as crianças seja uma forma de entendermos a infância a partir do ponto de vista das crianças. Neste artigo, especificamente, não se pretende analisar os resultados da pesquisa realizada, mas sim refletir acerca das possibilidades e limites que a pesquisa realizada com crianças nos impõe, sendo essa uma nova vertente de estudos, desenvolvida pela Sociologia da Infância, a qual vem apresentando um novo olhar sobre a criança, proporcionando-lhe o seu reconhecimento não apenas como reprodutora, mas também como construtora de cultura e de saberes que precisam ser respeitados.

A pesquisa com crianças apresenta diversas possibilidades de ver e compreender as crianças, seus pontos de vista, bem como de reconhecê-las enquanto sujeitos culturais, sociais, históricos e possuidores de direitos, os quais precisam ser considerados. O texto está organizado em quatro seções, na primeira são apresentadas algumas reflexões acerca da Sociologia da Infância e suas contribuições para a valorização do protagonismo infantil. A segunda seção aborda questões acerca de pesquisas com crianças e sua importância para a valorização da infância. Na terceira seção é apresentado um relato da pesquisa desenvolvida com as crianças mostrando algumas possibilidades e limites encontrados no desenvolvimento da investigação e, para finalizar, são tecidas algumas considerações sobre a temática.

\section{AS CRIANÇAS E A INFÂNCIA SOB O VIÉS DA SOCIOLOGIA DA INFÂNCIA}

Entendida como um campo científico, a Sociologia da Infância vem sendo cada vez mais reconhecida pela forma com que defende a infância e o protagonismo das crianças na sociedade. Ela busca entender o universo infantil e perceber as crianças como sujeitos ativos, socializadores, pensantes, os quais interagem, falam, sentem e se fazem presentes na sociedade, requerendo, por essas razões serem respeitados. A Sociologia da Infância 
busca, também, por meio de seus referenciais, entender que as crianças são sujeitos ativos, produtores de cultura e não apenas reprodutores, as quais constroem suas histórias e têm capacidades para viver ativamente na sociedade, expressando-se, manifestando suas vontades e, desse modo, sendo reconhecidas.

As crianças por muito tempo tiveram suas identidades desconsideradas; não se acreditava que elas tivessem condições de participar ativamente da sociedade, sendo totalmente dependentes e subordinadas aos interesses dos adultos, os quais eram também denominados como os seus porta-vozes, já que as crianças não possuíam o direito à voz ativa. Para Sarmento (2005), foi a partir da desconstrução desse conceito de socialização e da nova perspectiva apresentada pela Sociologia da Infância, que as crianças passaram a ser percebidas como "seres sociais plenos, dotados de capacidade de ação e culturalmente criativos" (p. 374).

A partir de 1990, estudos sob os princípios da Sociologia da Infância ganham força no Brasil, sendo decorrentes de estudos desenvolvidos por pedagogos e sociólogos (ABRAMOWICZ; OLIVEIRA, 2010). Tais estudos têm contribuído para um novo entendimento sobre as crianças e seus modos de atuação na sociedade. Dessa forma, a presença da Sociologia da Infância vem corroborando para novos entendimentos, novos questionamentos e novos estudos sobre a atuação e participação das crianças na sociedade, especialmente no contexto educativo.

Acontece também uma interlocução com outras áreas de conhecimento numa relação interdisciplinar pensando um campo mais amplo - Estudos da Criança - para dar conta da complexidade que reveste a criança e seus mundos de vida hoje. Esta interlocução tem permitido o desenvolvimento da área e uma sensibilidade maior para escutar a criança (DORNELLES; FERNANDES, 2015). A perspectiva interdisciplinar possibilita um lugar de encontro para diversos olhares sobre a infância e propicia um direcionamento para políticas mais centradas numa visão holística e interdependente nas relações e direitos das crianças.

Portanto, trilhar nos estudos da criança exige uma permanente interlocução com outros campos de conhecimento que consolida possibilidades metodológicas apropriadas para envolver as crianças na construção do conhecimento de si. Concretamente, isso exige uma nova concepção na forma de considerar ontologicamente a criança como sujeito de 
conhecimento e na forma de epistemologicamente valorizar tal conhecimento como legítimo. Para isso é necessário ter um pensamento prudente para não banalizar e comprometer os posicionamentos ético-metodológicos sobre a participação da criança na pesquisa (DORNELLES; FERNANDES, 2015).

Por muito tempo a educação das crianças foi vista de forma vertical, os professores detinham o poder do conhecimento e da fala e as crianças o dever de ouvir. A Sociologia da Infância defende um modelo de educação horizontal baseado no diálogo, na troca de experiências e saberes, em que a criança enquanto sujeito ativo que é, possa contribuir, ser escutada, tendo mais autonomia no processo educativo e liberdade de expressão.

Nessa ótica, Abramowicz e Oliveira (2010) pontuam que a Sociologia da Infância inaugurou uma nova forma de entender as crianças no contexto das instituições educativas, desvinculando-as do papel de aluno, passando a reconhecê-las enquanto crianças. Ao serem vistas como alunos, são vistas na homogeneidade; ao serem reconhecidas como crianças, estão sendo percebidas através da heterogeneidade presente na infância.

A valorização da heterogeneidade na infância se justifica, pelo fato de que ela se compõe de vários aspectos que precisam ser considerados, dentre os quais destacam-se: raça, etnia, classe social, gênero, espaço geográfico, fatores esses que interferem na forma com que as crianças vivem, agem e relacionam-se com o mundo. Assim, cabe às instituições educativas perceberem as crianças e suas diversidades, não reduzindo-as ao papel de aluno e de sujeitos homogêneos.

No atual contexto social em que as crianças estão inseridas, a escuta deve ser uma dinâmica diária no contexto educativo, pois elas carregam muitos saberes e experiências que precisam ser considerados pelos educadores, no entanto, isso só ocorrerá se tivermos a consciência de que as crianças possuem singularidades e características próprias, que elas também são sujeitos de direitos e precisam ser valorizadas como tal. É nessa ótica que Corsaro (2011, p. 31) considera que a Sociologia da Infância rompe com o conceito de socialização apresentado por Durkhein e inaugura o conceito de "reprodução interpretativa", o qual entende que "as crianças criam e participam de suas próprias e exclusivas culturas de pares quando selecionam ou se apropriam criativamente de informações do mundo adulto para lidar com suas próprias e exclusivas 
preocupações". Essa cultura passa a ser apropriada a partir da interação que a criança realiza, seja com seus familiares, amigos e pessoas à sua volta. O referido autor explica que a cultura de pares pode ser definida como o estabelecimento de relações entre os sujeitos, por meio do qual são compartilhadas culturas, saberes e experiências.

Nesse sentido, Abramowicz e Oliveira (2010) acreditam que a Sociologia da Infância passou a pensar nas crianças como sujeitos e atores sociais que constroem suas infâncias, rompendo com o paradigma que prevaleceu, por longo tempo, sobre uma infância passiva. Assim, essa área permite a elaboração de novas metodologias, entendendo as crianças como produtoras de culturas, a partir de si mesmas. As crianças possuem um jeito próprio de ser e de estar no mundo, elas são sujeitos autênticos, interativos e dialógicos, que no processo de interação estabelecem trocas, criam e compartilham experiências, enriquecendo seus modos de viver e agir na sociedade.

Faz-se também necessário entender que as crianças são o hoje, elas estão presentes na sociedade e precisam ser pensadas em seu tempo atual, e não apenas projetadas para o futuro. Corsaro (2011, p. 18) menciona que "é comum que os adultos vejam as crianças de forma prospectiva, isto é, em uma perspectiva do que se tornarão [...] raramente as crianças são vistas de uma forma que contemple o que são - crianças com vida em andamento". Compete, então, principalmente aos educadores, defender que as crianças sejam reconhecidas em seu tempo presente, em suas necessidades e em seus desejos atuais.

Essa forma de entender as crianças com base no presente, escutando-as e respeitando-as em suas necessidades, torna-se o principal desafio proposto para a Educação Infantil contemporânea. Portanto, "buscar formas de escutar as crianças, explorando as suas múltiplas linguagens, tem como pressupostos a crença de que elas têm o que dizer e o desejo de conhecer o ponto de vista delas", conforme nos apresenta Cruz (2008, p. 13).

E nessa perspectiva, justifica-se a importância de escutarmos as crianças, e por meio desse ouvir, termos condições de entender suas especificidades, seus anseios e valorizálas enquanto sujeitos que têm vozes e opiniões, as quais podem ser aplicadas no processo educativo. A partir dessa escuta, torna-se possível pensar num ambiente que venha ao encontro das reais necessidades das crianças, melhorando a relação entre professor- 
criança e, consequentemente, oferecendo uma melhor aprendizagem e consequente desenvolvimento.

\section{A SOCIOLOGIA DA INFÂNCIA COMO CAMPO DE CONHECIMENTO E PESQUISA: a participação infantil}

O desenvolvimento de pesquisas nas quais as crianças não sejam consideradas objetos de investigação, mas sim coparticipantes do processo investigativo, é uma das principais veias propulsoras da Sociologia da Infância. O ato de escutar as crianças no processo investigativo e tê-las como protagonistas desse processo, é uma nova forma de reconhecimento da infância e das peculiaridades infantis e vem cada vez mais sendo desenvolvida por pesquisadores que se dedicam a estudar a infância.

Embora pequena, a criança não está inserida num micromundo, portanto, é importante mobilizar sua participação nos processos de pesquisa possibilitando que pensem e falem sobre suas experiências práticas. Ao pesquisar com as crianças e não sobre as crianças, inaugura-se uma nova forma de investigação acerca desses sujeitos, preocupando-se "em capturar as vozes infantis, suas perspectivas, seus interesses e direitos como cidadãos" (CORSARO, 2011, p.56).

Desse modo, as crianças passam a ser além de construtores, contadores de suas histórias, a terem os seus lugares cada vez mais ocupados e reconhecidos na sociedade. A pesquisa passa a ser um forte mecanismo de valorização da infância e a auxiliar as diferentes esferas da sociedade a compreenderem a importância da escuta infantil, definida como uma importante estratégia para pensar, planejar e organizar as ações voltadas às crianças, especialmente, no contexto educativo.

A prática de não escutar as crianças está diretamente relacionada à história da infância, de acordo com Francischini e Campos (2008, p. 103), "a representação da infância, enquanto referida a um sujeito com estatuto próprio, ocupando, portanto, um lugar social específico, é uma construção delineada pela modernidade". Para Corsaro (2011), a ausência das crianças nas pesquisas ao longo da história se deve às condições de invisibilidade que elas tinham em relação aos adultos e à sociedade. 
De acordo com Belloni (2009), a infância foi negligenciada por muito tempo nas pesquisas educacionais, sendo essa realidade transformada pela Sociologia da Infância, quando os grupos minoritários e excluídos da sociedade passaram a aparecer com mais amplitude nas pesquisas, como é o caso da infância e da mulher. A referida autora expõe:

Somente ao final do século $\mathrm{XX}$ os estudos sociológicos chegaram a um novo patamar, descobrindo a infância como categoria e objeto de estudo pleno e relevante, passando a considerar as crianças atores importantes nas interações sociais, e tentando construir novos paradigmas de compreensão desses fatos sociais, a partir do questionamento das oposições e dicotomias da modernidade e dos conceitos clássicos de socialização (BELLONI, 2009, p. 122).

Corsaro (2011) considera que escutar as crianças nas pesquisas por meio de métodos coerentes com suas condições seja uma forma de entender como elas constroem os sentidos e contribuem com os processos de reprodução e mudanças sociais, sendo, ainda, uma forma de valorizá-las enquanto sujeitos produtores de cultura, que não apenas reproduzem, mas também produzem saberes, os quais podem ser compartilhados. Essa participação das crianças nas pesquisas tem significado um grande avanço para o reconhecimento da infância, no entanto, o desenvolvimento de pesquisas com crianças, e não sobre crianças, é algo novo, que muitas vezes intimida o pesquisador a desenvolver tal prática. O desenvolvimento desse tipo de pesquisa exige cuidados específicos por parte do pesquisador para que as crianças sejam, de fato, respeitadas como protagonistas de suas histórias.

Cabe, ao pesquisador, primeiramente criar vínculos com os sujeitos pesquisados, contribuindo para que as crianças se sintam confiantes e seguras com a presença do pesquisador. Há ainda que procurar, enquanto pesquisador, ser aceito pelas crianças e pelo seu mundo, diminuindo a representação de autoridade e poder que os adultos representam.

Ao pesquisar com as crianças, é preciso ainda ter ciência de que em primeiro lugar estará o bem-estar delas e de que, assim como em todo trabalho investigativo, imprevistos poderão acontecer, daí a importância e a seriedade com que a pesquisa com crianças precisa ser desenvolvida. Ao pesquisar com as crianças é preciso ser cuidadoso em relação à condição da infância; ao pesquisador, faz-se necessário que conheça as crianças e suas 
características, a fim de respeitá-las e conduzir o trabalho priorizando sempre o bem-estar dos sujeitos. A necessidade de conhecer as crianças se justifica, ainda, pelas múltiplas linguagens que elas possuem, o que permite que se manifestem de diversas maneiras nas pesquisas.

Pesquisar com as crianças envolve metodologias diferenciadas e variadas, pois elas possuem características que as diferenciam do adulto. Nesse sentido, as metodologias investigativas com crianças, na qual se procura possibilitar voz a esse público e reconhecê-las como coparticipantes desse processo, implica a utilização de métodos compatíveis com essa participação e com a realidade apresentada pelos sujeitos envolvidos. O desenho metodológico não pode estar fechado e nem ser replicado por qualquer pessoa e tempo nos alertam Dornelles e Fernandes (2015), sendo necessário investir em novos caminhos investigativos.

Oliveira, Formosinho e Araújo (2008) destacam alguns cuidados que precisam ser tomados ao desenvolver pesquisas com as crianças. $O$ pesquisador precisa possuir 0 consentimento escrito dos pais ou responsáveis, autorizando a participação das crianças; garantir o sigilo e a privacidade em relação à identidade dos sujeitos; exercitar o diálogo durante a pesquisa com as crianças, explicando sobre todos os procedimentos realizados; respeitar, durante o processo, se as crianças não quiserem continuar a participar; tomar o devido cuidado com a linguagem utilizada no diálogo com as crianças e com as condições do espaço físico proposto para a escuta, o qual precisa oferecer plenas condições para a segurança das crianças, além dos cuidados éticos.

Vale ressaltar que formalmente, nem sempre as crianças podem consentir pela sua participação nas pesquisas, no entanto, esse assentimento por parte delas, é fundamental para a realização do trabalho investigativo. De acordo com Coutinho (2015) cabe ao pesquisador encontrar meios que possibilitem a captura dessas autorizações por parte das crianças.

O maior desafio ético para o pesquisador é a disparidade de poder entre adultos e crianças. É necessário refletir sobre a complexidade que envolve a voz da criança na pesquisa, não é um simples registrar e gravar. As crianças têm muito a dizer, sugerem caminhos, nos ensinam a ousar. Também querem a autoria da pesquisa. Dar autoria à criança é usarmos da possibilidade de ir além do que é reconhecível e sustentarmos a 
autoria composta por crianças e adultos. Investir numa ética particular de autoria das crianças vai além de ser apenas escriba das mesmas, pois em toda pesquisa com crianças nos reinventamos como pesquisadores (DORNELLES; FERNANDES, 2015).

A partir do conceito de reprodução interpretativa inaugurado pela Sociologia da Infância, as crianças têm totais condições de exercer sua participação ativa nas pesquisas. “[...] são competentes e têm capacidade de formularem interpretações da sociedade, dos outros e de si próprios, da natureza, dos pensamentos e dos sentimentos, de o fazerem de modo distinto e de usarem para lidar com tudo que os rodeia" (SARMENTO, 2005, p. 377).

As crianças passam a ter o direito de se expressarem, de apresentarem suas realidades, sem camuflagem, sem terem suas próprias histórias contadas pelos outros, podendo compartilhar o seu mundo e se fazendo reconhecidas e respeitadas pelos adultos. Esta afirmativa é defendida por Soares, Sarmento e Tomás (2005):

\begin{abstract}
A Sociologia da Infância, ao assumir que as crianças são actores sociais plenos, competentes na formulação de interpretações sobre os seus mundos de vida e reveladores das realidades sociais onde se inserem, considera as metodologias participativas com crianças como um recurso metodológico importante, no sentido de atribuir aos mais jovens o estatuto de sujeitos de conhecimento, e não de simples objeto, instituindo formas colaborativas de construção do conhecimento nas ciências sociais que se articulam com modos de produção do saber empenhados na transformação social e na extensão dos direitos sociais (SOARES; SARMENTO; TOMÁS, 2005, p. 54).
\end{abstract}

Qvortrup (1991) citado por Corsaro (2011, p. 58) ressalta que a pesquisa que envolve crianças torna-se "essencial para identificar os fatores que contribuem para a diversidade da infância e da vida cotidiana infantil”. A partir da inserção das crianças como sujeitos participantes nas pesquisas e não como meros objetos, elas passaram a ser vistas e reconhecidas "como atores sociais em seu próprio direito, e os métodos são adaptados e refinados para melhor ajuste às suas vidas" (CORSARO, 2011, p. 57).

O processo de escuta das crianças é de extrema importância para conhecê-las melhor, compreender suas necessidades, seus pontos de vista sobre o mundo ao seu redor. Nesse sentido, Oliveira Formosinho e Araújo (2008) pontuam que o ato de escutar as crianças é um direito que elas têm assegurado e, muitas vezes, é visto como uma concessão que generosamente o adulto Ihes concede. Escutar o que as crianças têm a dizer é de 
grande valia, pois, por meio dessa escuta se torna possível analisar as realidades sob a ótica delas, que têm uma percepção diferente dos adultos, uma maneira própria de ver o mundo. O progresso nas pesquisas com crianças se efetivará mediante a escuta das crianças e da atenção à forma como se comunicam.

\section{UMA EXPERIÊNCIA DE ESCUTA NO CONTEXTO EDUCATIVO: possibilidades de reconhecimento das vozes infantis}

Desenvolver a escuta infantil é uma proposta que deve estar presente em várias instâncias da sociedade, no entanto, ela se torna necessária no contexto educativo, uma vez que os espaços institucionais, especialmente os da Educação Infantil, são muitas vezes, onde as crianças passam a maior parte de seus dias; portanto, devem ser abertos ao diálogo e à participação efetiva das crianças, em seus cotidianos e em suas rotinas. Sob esta visão, Rocha (2008) entende que a escuta das crianças contribui para o reconhecimento de seus direitos no ambiente educativo, contudo, a autora defende que apenas ouvir as crianças não basta, sendo preciso, além disso, garantir sua efetiva participação nas práticas educativas no contexto das instituições. Essa escuta é, ainda, um importante mecanismo para se repensar a Educação Infantil, assim propõem, Oliveira Formosinho e Araújo (2008, p. 79):

\footnotetext{
Na Educação Infantil, as informações que as crianças podem dar são relevantes para se conhecer melhor o que se passa nas instituições de cuidado e educação de crianças pequenas e também para entender como elas veem os processos que aí se desenvolvem, como se sentem, o que temem, o que desejam na sua experiência educativa.
}

Essa concepção mencionada pelas autoras, auxilia a entender melhor o universo infantil, suas características, suas necessidades e suas formas de agir na sociedade. Para o acesso a ação e voz da criança são necessários uma variedade de instrumentos que se justificam pelo fato de as crianças se expressarem por meio de formas variadas, cabendo, ao pesquisador, o cuidado de respeitar esses modos diversos e não perder as informações repassadas por elas. Leite (1996, p. 80) aponta que "[...] quanto maior o leque de opções para a expressão, mais portas abrimos para nossa escuta”. 
Neste contexto, originou-se a pesquisa de mestrado, a qual objetivou entender o que as crianças de uma turma de pré-escola, na faixa etária de 04 a 05 anos, manifestam sobre a instituição educativa que frequentavam, buscando respeitar os limites e as necessidades infantis, bem como a superar a visão adultocêntrica do pesquisador diante da criança. Ao escolher pesquisar com as crianças, dúvidas, questionamentos e inseguranças vieram à tona. Como realizar a pesquisa? Como propor formas para escutar as crianças? Que metodologias utilizar? Que posturas adotar enquanto pesquisadora para possibilitar a participação e o protagonismo das crianças?

Essas e outras dúvidas impulsionaram a busca por trabalhos já desenvolvidos sobre essa temática. A busca possibilitou novos conhecimentos e novas ideias para a elaboração da investigação, assim como a realização de leituras e estudos sobre o tema. As buscas e os estudos desenvolvidos, demandaram dedicação, tempo, trouxeram desafios, mas foram essenciais para a realização e conclusão da pesquisa. O fato de não existirem muitos trabalhos desenvolvidos sobre a problemática apresentada, foi motivo de dificuldades para ter um embasamento e construir o projeto de pesquisa, o qual foi sendo reformulado, a partir da realização da pesquisa no campo.

Vale destacar que uma das principais características do trabalho investigativo com as crianças esteja na flexibilidade, pois mesmo o pesquisador tendo desenvolvido seu projeto e planejado suas ações, é no contexto com as crianças que esse, vai de fato sendo construído, já que as crianças possuem formas próprias de interagirem, agirem e manifestarem-se. De acordo com Leite (1996), quando nos dispomos a pesquisar com as crianças, essa característica da flexibilidade há de ser levada em conta, pois as opções de expressões que são disponibilizadas na pesquisa, influenciarão nas informações que elas trarão e nas possibilidades de escutá-las.

Durante a pesquisa, planejamos escutar as crianças de diferentes formas, a fim de considerar as múltiplas linguagens presentes na infância, porém, algumas formas de escuta, se alteraram no momento da inserção no campo. Foram então desenvolvidos os seguintes procedimentos metodológicos: observação participante, para conhecer e criar vínculo com as crianças; análise documental, para conhecer a visão e intenção educativa da instituição; entrevistas coletivas com as crianças, as quais contaram com a presença de fantoches para a mediação dos diálogos entre pesquisadora e crianças; registros 
fotográficos também desenvolvidos pelas crianças e realização de desenhos sobre a instituição, por parte das crianças.

A observação participante foi fundamental para a realização da pesquisa, ela realizou-se duas vezes na semana, pelo período de dois meses, possibilitou conhecer as crianças, observar como elas interagem, como estabelecem relações, resolvem conflitos. A partir dessa participação, foi possível criar um vínculo com as crianças participantes da pesquisa, o qual foi essencial para o estabelecimento de confiança e da realização da investigação.

Já as entrevistas, as quais objetivavam por meio do diálogo conhecer o que as crianças expressam sobre a instituição, foram realizadas de forma coletiva, envolvendo pequenos grupos de crianças, pois segundo Cruz (2008) quando se envolve mais de uma criança no diálogo, elas se sentem mais confortáveis, pois, dessa forma, a imagem de autoridade que o pesquisador representa é atenuada.

Durante as entrevistas, foram utilizados fantoches para mediar o diálogo. Essa técnica do uso de fantoches durante a entrevista, é sugerida por Oliveira, Formosinho e Araújo (2008), que destacam que alguns recursos podem ser empregados pelo pesquisador no momento da entrevista, como forma de melhor envolver as crianças, ampliando as possibilidades de participação, minimizando as inseguranças e diminuindo a autoridade representada pelo pesquisador.

As entrevistas foram desenvolvidas em duas datas diferentes, na primeira data, por meio de uma encenação, as crianças apresentavam a instituição para um novo amigo, o qual foi representado por um fantoche. Durante o diálogo, as crianças contaram ao novo amigo tudo que há na instituição, o que fazem enquanto permanecem nela, o que gostam de fazer e o que não gostam, quais os seus espaços preferidos da instituição. Na segunda data, também representado por um fantoche, o amigo gostaria de saber o que não é legal na instituição, assim as crianças relataram o que sentem falta quando estão na instituição, o que gostariam que tivesse e não tem, o que não gostam de fazer e quais espaços não Ihes agradam.

Os registros fotográficos foram desenvolvidos com o objetivo de as crianças registrarem por meio de fotos, os seus espaços preferidos da instituição. Soares, Sarmento e Tomás (2005, p. 60) consideram que "encarar as crianças como competentes para o 
manuseamento de equipamentos de registo em vídeo e em fotografia é uma atitude indispensável para Ihes facultar documentar e tornar visíveis as suas representações acerca do mundo que as rodeia".

A primeira tentativa de realizar o passeio pela instituição com as crianças e fazer os registros fotográficos aconteceu após um diálogo explicativo sobre a realização da pesquisa. Esse momento de diálogo aconteceu à sombra de uma árvore, durante o diálogo, informei as crianças sobre a proposta do passeio e sobre os registros fotográficos; todos aceitaram participar, as crianças foram organizadas em dois grupos, sendo cada um composto por quatro crianças, no entanto, no momento que iniciamos o passeio, elas correram, foram brincar e pouco dialogam sobre os espaços.

Na pesquisa com crianças, é necessário respeitar as suas manifestações e os seus desejos, ter a sensibilidade de reconhecer tais aspectos e adaptar a pesquisa aos interesses apresentados pelos sujeitos, uma vez que esse respeito é fator fundamental para o desenvolvimento da pesquisa com seres humanos, especialmente com crianças. Durante os passeios, as crianças demonstraram sentir liberdade, alegria e ansiedade; riam, dialogavam, corriam querendo explorar tudo à sua volta. Desse modo, mesmo não tendo conseguido, nesse momento, que fizessem os registros fotográficos da instituição, a ação me possibilitou riquíssimas análises, pois os comportamentos demonstrados pelas crianças evidenciaram que, para elas, naquele momento o mais importante era o brincar, era uma novidade passearem pela instituição e me apresentarem os espaços.

Após diálogo com a orientadora e realização de novos estudos sobre a pesquisa com crianças, a ação dos registros fotográficos foi reelaborada, a qual só foi possível, após entender que as crianças possuem diferentes formas de se expressarem e que, nós adultos, precisamos ser sensíveis à escuta infantil e às necessidades por elas apresentadas. A segunda tentativa então, ocorreu após uma das entrevistas. Explicamos às crianças sobre a atividade proposta e todas aceitaram participar. Nesse dia, optamos por organizá-las em duplas. Primeiramente conversamos sobre os espaços, elas relataram qual era o lugar da instituição de que mais gostavam, após o diálogo seguíamos até o espaço, onde elas fizeram o registro fotográfico. Vale ressaltar que algumas crianças fotografaram mais de um espaço, já outras tiveram dificuldades em escolher o espaço preferido. 
Nesse dia, as crianças participaram, conversaram pelo caminho, algumas não queriam voltar para a sala, pedindo para fazer o passeio novamente. Com essa nova dinâmica, conseguimos desenvolver melhor a proposta, dialogar com todas as crianças e envolvê-las melhor na ação. De acordo com Soares, Sarmento e Tomás (2005, p. 60), a investigação participativa com crianças precisa possibilitar a escuta dos sujeitos a partir de uma multiplicidade de recursos metodológicos, os quais possam "tornar audíveis as vozes de todas as crianças".

Com essa reconfiguração do passeio, as crianças mais tímidas, que não haviam se expressado em outros momentos da pesquisa, conversaram durante o trajeto para o espaço escolhido, explicando sobre sua escolha com mais segurança e menos timidez. Merece destaque o fato de os passeios ocorrerem de forma livre, sem haver um roteiro pré-estabelecido para o diálogo. Isso possibilitou que as crianças dialogassem com liberdade, contando sobre suas vidas, sobre fatos de seus cotidianos, assim como demonstrando curiosidade pelas plantas, insetos, pássaros que eram encontrados pelo caminho.

O uso do registro fotográfico como procedimento metodológico nesta pesquisa possibilitou escutar as crianças sobre seus espaços preferidos da instituição e reconhecer que elas têm muito a dizer; escutá-las pode ajudar na organização e no planejamento da instituição educativa.

Em relação aos registros por meio de desenhos, eles representam uma das linguagens infantis, expressam desejos, culturas e revelam sentimentos. Sarmento (2011) entende que o desenho seja uma das mais importantes formas de expressão infantil, por meio dele é possível identificar como as crianças apreendem e incorporam o mundo à sua volta; é uma linguagem infantil que comunica por meio da imagem aquilo que a linguagem verbal nem sempre expressa.

Com esse recurso, procuramos que as crianças desenhassem e destacassem o que mais gostavam na instituição. Durante a produção dos desenhos, conversamos individualmente com cada criança, na intenção de escutar sobre o que cada uma estava desenhando. Como alguns desenhos não apresentavam formas definidas, foi necessário que, ao lado das figuras, ficasse registrado o que cada criança interpretou do seu desenho. 
Todas as crianças presentes participaram da ação, porém, algumas não demonstraram interesse em finalizar seus desenhos e os entregaram assim que achavam necessário; do mesmo modo, algumas crianças explicavam claramente sobre seus registros, já outras não demonstraram muito interesse em esclarecê-lo. Mesmo tendo sido orientadas a desenhar sobre a instituição, todas tiveram liberdade para desenhar de acordo com suas vontades. Diversos desenhos não apresentaram nenhuma relação com a instituição, algumas crianças até mesmo justificaram que não quiseram desenhar sobre a instituição. Sarmento (2011) considera que os desenhos produzidos pelas crianças estabelecem constante relação com suas culturas e com seus modos de vida. Eles possibilitam identificar as formas próprias que cada criança tem de ver e entender o mundo a sua volta

Não objetivamos neste texto apresentar os resultados que a pesquisa evidenciou. Buscamos refletir sobre a importância, as possibilidades e os desafios de desenvolver uma pesquisa com as crianças, a qual contribui significativamente para a compreensão da infância, das necessidades infantis e de atendimento nos ambientes educativos para com as crianças que ali estão inseridas.

\section{TECENDO ALGUMAS CONSIDERAÇÕES}

Nos últimos trinta anos muitos avanços ocorreram quanto ao reconhecimento das crianças como sujeitos com características próprias que precisam ser escutadas e respeitadas em contraposição à negatividade instituída pela modernidade de uma imagem de criança submissa à autoridade do adulto, retratada pela ausência de voz e ação, que invisibiliza as crianças e suas realidades sociais. Esses avanços advêm das legislações voltadas à infância, das novas formas de organização da sociedade, da Educação Infantil e do surgimento da Sociologia da Infância, a qual tem contribuído significativamente para as crianças serem reconhecidas a partir de suas especificidades. No entanto, muito ainda precisa ser feito, com relação às crianças, especialmente com relação a participação efetiva desses sujeitos, no contexto educativo e na sociedade.

As pesquisas com a participação das crianças têm se mostrado um espaço problematizador de discussão e reflexão, valorizando o protagonismo infantil e assim 
contribuindo com o processo educativo com vistas a uma maior qualidade do trabalho, pois as práticas institucionais geralmente são planejadas e organizadas pelos adultos, sendo as crianças apenas reprodutoras de tais ações.

O desenvolvimento de pesquisas com crianças como espaço problematizador de discussão e reflexão têm debatido essa questão, se tornando meio de considerar a participação e valorizar o protagonismo infantil, especialmente para melhorar a educação, pois as práticas institucionais geralmente são pensadas, planejadas e organizadas pelos adultos, sendo as crianças apenas reprodutoras de tais ações.

Se suas vozes e proposições forem escutadas e consideradas, podem contribuir para a melhoria do processo educativo, pois crianças são sujeitos culturais, seus direitos formam um conjunto de valores consagrados em legislações nacionais e internacionais que se destinam a fazer respeitar e concretizar determinados princípios e condições de vida para as crianças.

Ainda encontramos dificuldades de escutá-las e considerar suas vozes e proposições para a melhoria do processo educativo. É necessário compreender que as crianças são seres culturais, seus direitos formam um conjunto de valores consagrados em legislações nacionais e internacionais que se destinam a fazer respeitar e concretizar determinados princípios e condições de vida para as crianças. No entanto, assistimos a um certo desconhecimento por parte dos adultos do que são e do que implicam.

Portanto, ainda se faz necessário avançar no debate sobre a participação infantil e as metodologias cujos focos sejam as vozes e as ações das crianças, em razão de ser um caminho longo a ser percorrido e que vem sendo crescentemente trilhado.

Uma das dificuldades encontradas na realização de uma pesquisa com crianças é compreender o significado e as características desse tipo de pesquisa, pois na academia, muitas vezes nos deparamos com conceitos rígidos sobre pesquisa e a pesquisa com crianças se apresenta de forma mais flexível, pois objetiva principalmente atender as necessidades e as características da infância. Para estarmos com as crianças e tornarmos audíveis suas vozes e visíveis suas ações precisamos colocar em suspensão nossas verdades e apontar novas formas de problematizar o já conhecido.

Compreender a ética na pesquisa com a criança se relaciona a compreendermos a criança como ator social, o que nos coloca novos dilemas e responsabilidades, sendo o 
maior desafio para o pesquisador manter uma relação horizontal e dialógica com a criança. Uma investigação que priorize a criança precisa criar metodologias que captem suas ações sociais, as linguagens e os significados que colocam nas palavras, enfim, construir junto com a criança a pesquisa.

Para que essa construção conjunta aconteça precisamos manter uma vigilância epistemológica e um posicionamento crítico frente às nossas relações sociais e pedagógicas com as crianças em busca de posturas e concepções coerentes de respeito e diálogo entendendo que as crianças são, de acordo com Sarmento (2005), atores sociais, e assim devem ser compreendidas, para que possam agir, atuar e se constituírem como sujeitos, construindo suas culturas e apropriando-se do mundo à sua volta.

\section{REFERÊNCIAS}

ABRAMOWICZ; Anete; OLIVEIRA, Fabiana. A sociologia da infância no Brasil: uma área em construção. Revista Educação, v. 35, n. 1, p. 39-52, jan./abr. 2010.

BELLONI, Maria Luiza. O que é sociologia da infância. Campinas-SP: Autores Associados, 2009.

CORSARO, Willian A. Sociologia da infância. Porto Alegre: Artmed, 2011.

COUTINHO, Angela Scalabrin. Pesquisa interpretativa com crianças bem pequenas. In: ENS, Romilda Teodora; GARANHANI, Marynelma Camargo. (Orgs.). Pesquisa com crianças e a formação de professores. Curitiba: PUCPRess, 2015.

CRUZ, Silvia Helena Vieira. A qualidade da educação infantil, na perspectiva das crianças. In: FORMOSINHO, Julia Oliveira (org.). A escola vista pelas crianças. Porto: Porto Editora, 2008.

DORNELLES, Leni Vieira; FERNANDES, Natalia. Estudos da Criança e pesquisa com crianças: nuances luso-brasileiras acerca dos desafios éticos e metodológicos. Currículo e Fronteiras. v.15, n.1, p. 65-78, jan - abr, 2015.

FERNANDES, Natália; TREVISAN, Gabriela de Pina. Cidadania Ativa: roteiros metodológicos. In: ALBERTO, Fátima; PICORNELL, Antonia. (Org.). Experiencias Mundiales de cidadania de la infância e adolescência. Baía, Editora UFPB, 2018, p. 212-139. 
FRANCISCHINI, Rosângela; CAMPOS, Herculano Ricardo. Crianças e infâncias, sujeitos de investigação: bases teórico-metodológicas. In: CRUZ, Silvia Helena Vieira (Org.). A criança fala: a escuta de crianças em pesquisas. São Paulo: Cortez, 2008.

LEITE, Maria Isabel Ferraz Pereira. O que falam de escola e saber as crianças da área rural? Um desafio da pesquisa no campo. In: KRAMER, Sonia; LEITE, Maria Isabel. (Orgs.). Infância: fios e desafios da pesquisa. 12. ed. Campinas-SP: Papirus, 1996.

OLIVEIRA-FORMOSINHO, Júlia; ARAÚJO, Sara Barros. Escutar as vozes das crianças como meio de (re)construção de conhecimento acerca da infância: algumas implicações metodológicas. In: OLIVEIRA-FORMOSINHO, Júlia (Org.). A escola vista pelas crianças. Porto-Portugal: Porto Editora, 2008.

ROCHA, Eloisa Acires Candal. Por que ouvir as crianças? Algumas questões para um debate científico multidisciplinar. In: CRUZ, Silvia Helena Vieira (Org.). A criança fala: a escuta de crianças em pesquisas. São Paulo: Cortez, 2008.

SARMENTO, Manuel Jacinto. Conhecer a infância: os desenhos das crianças como produções simbólicas. In: FILHO, Altino José Martins; PRADO, Patrícia Dias. Das pesquisas com crianças: à complexidade da infância. Campinas-SP: Autores Associados, 2011.

SARMENTO, Manuel Jacinto. Gerações e alteridade: interrogações a partir da sociologia da infância. Revista Educação e Sociedade, v. 26, n. 91, p. 361-378, maio/ago. 2005.

SOARES, Natália Fernandes; SARMENTO, Manuel Jacinto; TOMAS, Catarina. Investigação da infância e crianças como investigadoras: metodologias participativas dos mundos sociais das crianças. Nuances: estudos sobre educação, ano XI, v. 12, n. 13, jan./dez. 2005.

Enviado em: 26-08-2020

Aceito em: 13-10-2020

Publicado em: 05-01-2021 